\title{
Prospective European-wide multicentre study on a blood based real-time PCR for the diagnosis of acute schistosomiasis
}

\author{
Dominic Wichmann ${ }^{1 *}$, Sven Poppert ${ }^{2}$, Heidrun Von Thien ${ }^{2}$, Joannes Clerinx ${ }^{3}$, Sebastian Dieckmann ${ }^{4}$, \\ Mogens Jensenius ${ }^{5}$, Philippe Parola ${ }^{6}$, Joachim Richter ${ }^{7}$, Mirjam Schunk ${ }^{8}$, August Stich ${ }^{9}$, Philipp Zanger ${ }^{10}$, \\ Gerd D Burchard ${ }^{2,11}$ and Egbert Tannich ${ }^{2}$
}

\begin{abstract}
Background: Acute schistosomiasis constitutes a rare but serious condition in individuals experiencing their first prepatent Schistosoma infection. To circumvent costly and time-consuming diagnostics, an early and rapid diagnosis is required. So far, classic diagnostic tools such as parasite microscopy or serology lack considerable sensitivity at this early stage of Schistosoma infection. To validate the use of a blood based real-time polymerase chain reaction (PCR) test for the detection of Schistosoma DNA in patients with acute schistosomiasis who acquired their infection in various endemic regions we conducted a European-wide prospective study in 11 centres specialized in travel medicine and tropical medicine.

Methods: Patients with a history of recent travelling to schistosomiasis endemic regions and freshwater contacts, an episode of fever (body temperature $\geq 38.5^{\circ} \mathrm{C}$ ) and an absolute or relative eosinophil count of $\geq 700 / \mu \mathrm{l}$ or $10 \%$, were eligible for participation. PCR testing with DNA extracted from serum was compared with results from serology and microscopy.

Results: Of the 38 patients with acute schistosomiasis included into the study, PCR detected Schistosoma DNA in 35 patients at initial presentation (sensitivity 92\%). In contrast, sensitivity of serology (enzyme immunoassay and/or immunofluorescence assay) or parasite microscopy was only $70 \%$ and $24 \%$, respectively.

Conclusion: For the early diagnosis of acute schistosomiasis, real-time PCR for the detection of schistosoma DNA in serum is more sensitive than classic diagnostic tools such as serology or microscopy, irrespective of the region of infection. Generalization of the results to all Schistosoma species may be difficult as in the study presented here only eggs of $\mathrm{S}$. mansoni were detected by microscopy. A minimum amount of two millilitre of serum is required for sufficient diagnostic accuracy.
\end{abstract}

\section{Background}

Schistosomiasis is a parasitic infection with trematode flatworms of the genus Schistosoma. According to the World Health Organization (WHO) 200 million people in at least 76 countries are affected, most of them located in tropical and subtropical regions [1]. Most infections are attributable to three species: Schistosoma mansoni, S. haematobium, and S. japonicum [2]. The courses of human infections can

\footnotetext{
* Correspondence: d.wichmann@uke.de

1 Department of Intensive Care Medicine, University Medical Centre Hamburg-Eppendorf, 20246, Hamburg, Germany

Full list of author information is available at the end of the article
}

be divided into acute and chronic forms. Acute schistosomiasis, also known as Katayama syndrome [3,4], constitutes a fulminant allergic reaction with fever and eosinophilia and may be accompanied by skin, pulmonary, abdominal or even neurological symptoms. In general, these clinical courses are seen in patients experiencing their first Schistosoma infection and reflect an early immunological reaction against developing young worms during prepatency [5]. Accordingly, acute schistosomiasis is usually seen in non-immune travellers returning from Schistosoma endemic countries. Considering the broad differential diagnosis of fever and eosinophilia, an early and rapid diagnosis is

\section{Biomed Central}

(c) 2013 Wichmann et al.; licensee BioMed Central Ltd. This is an Open Access article distributed under the terms of the Creative Commons Attribution License (http://creativecommons.org/licenses/by/2.0), which permits unrestricted use, distribution, and reproduction in any medium, provided the original work is properly cited. 
required to circumvent unnecessary costly and timeconsuming diagnostic procedures. However, acute schistosomiasis constitutes a diagnostic challenge as classical tools often fail to detect the parasite at this early stage of infection. Parasite microscopy following Katz-Kato smears or concentration techniques for helminth eggs, lack sensitivity, in particular, in individuals with a low parasite burden and during the prepatent period [6]. In settings with low transmission rates or in patients with low parasite burden immunological tests may be more sensitive than parasite microscopy [7]. Nevertheless, a substantial number of patients remain serologically negative at initial presentation $[8,9]$. Moreover, the inability of serology to discriminate between active and past disease limits its clinical value for follow up investigations [10]. The detection of Schistosoma specific circulating anodic and cathodic antigens (CAA and CCA) in blood or urine, released by viable adult worms, has been tested in schistosomiasis endemic regions and sporadic experiences have been reported for the use in patients with acute schistosomiasis [11-13]. Because the sensitivity of these tests greatly depends on the worm burden, they are probably not suited for the diagnosis of schistosomiasis in travellers with rather low worm burden.

Recently, we reported on the development of a new real-time polymerase chain reaction (PCR) test for the detection of Schistosoma specific DNA in blood of infected individuals [14], which revealed excellent performance for the diagnosis of acute schistosomiasis in a small group of travellers returning from Rwanda [15]. Here we report on a European-wide multicenter study to evaluate the use of this PCR for the diagnosis of acute schistosomiasis in larger number of patients returning from various destinations.

\section{Methods}

\section{Study design}

Evaluation of blood based real-time PCR testing in travellers returning from schistosomiasis endemic regions with suspected acute schistosomiasis in 11 specialized European centres in a prospective study from January 2009 to April 2012. In detail the participating countries were Belgium, France, Norway and Germany. The sites are institutions specialised in tropical or travel medicine and are members of the EuroTravNet (www.istm.org/ eurotravnet/main.html) initiated by The International Society of Travel Medicine and which represents a collaborative network of the European Centre of Disease Control (ECDC). The study was approved by the Hamburg Ethics Committee of the Chamber of Physicians and complied with the Declaration of Helsinki. For the Oslo site data managing files were slightly modified according to local data security requirements, for the other sites no changes were required.

\section{Inclusion criteria}

Patients with a history of a recent travel to a schistosomiasis endemic region and freshwater contacts, an episode of fever (body temperature $\geq 38.5^{\circ} \mathrm{C}$ ) and an absolute or relative eosinophil count of $\geq 700 / \mu$ l or $\geq 10 \%$, were eligible for participation (Group $\mathrm{A} ; \mathrm{n}=38$ ). In addition, 17 patients with high clinical suspect of acute schistosomiasis but without an episode of fever were also tested (Group B). An amount of at least $2 \mathrm{ml}$ of serum was required for DNA extraction and PCR testing as well as for Schistosoma serology. Oral informed consent was obtained from every patient or their legal guardians.

\section{Microscopic parasite detection}

Microscopy of faecal or urine samples for the detection of Schistosoma eggs were done on individual decision of the attending physician at each centre according to established in-house protocols. In general, stool samples were analysed using the formol-ether concentration technique [16]. For detection of S. haematobium eggs, urine collected over a period of 24 hours or at least between 10 am and $2 \mathrm{pm}$ was filtered and processed as described earlier [17].

\section{Serum and plasma samples}

Samples were sent to Hamburg by mail at room temperature and analysed for anti-Schistosoma specific antibodies and Schistosoma DNA.

\section{Serology}

All patient sera were tested for anti-schistosoma antibodies using an enzyme-immunoassay (EIA) and an immunofluorescence-assay (IFA), respectively $[18,19]$.

\section{DNA preparation and real time PCR}

DNA preparation from $2 \mathrm{ml}$ serum was performed at the Bernhard Nocht Institute for Tropical Medicine, Hamburg, Germany, using the QIAamp Circulating Nucleic Acid Kit according to the manufacturers suggestion (Qiagen, Hilden, Germany). Detection of cell-free Schistosoma DNA was performed according to a previously published protocol [14]. The test targets the $121 \mathrm{bp}$ tandem repeat sequence first described by Hamburger et al. [20] using the primer sequences SRA1 (CCACGCTCTCGCAAATAATCT) and SRS2 (CAACCGTTCTATGAAAATCGTTGT) as previously reported [14]. All PCRs were performed in duplicate. A test was considered positive when the threshold was attained within 45 PCR cycles (Ct-value $<45)$.

\section{Diagnosis and treatment}

A patient was considered positive for acute schistosomiasis when either microscopy, serology or PCR testing revealed a positive result. Treatment with Praziquantel 
Table 1 Characteristics of patients with acute schistosomiasis fulfilling the inclusion criteria

\begin{tabular}{|c|c|c|c|c|c|c|c|c|}
\hline Patient & $\begin{array}{l}\text { Region of } \\
\text { exposure }\end{array}$ & $\begin{array}{l}\text { Reason for } \\
\text { travel }\end{array}$ & $\begin{array}{c}\text { Incubation time } \\
\text { [days] }^{(1)}\end{array}$ & $\begin{array}{l}\text { Time to diagnosis } \\
\text { [days] }]^{(2)}\end{array}$ & $\begin{array}{l}\text { Eosinophils absolute } \\
\text { [per } \mu \mathrm{l}]\end{array}$ & PCR & Serology & Microscopy \\
\hline 1 & Rwanda & Tourist & 57 & 62 & 5.400 & pos & pos & S.m. \\
\hline 2 & Rwanda & Tourist & 33 & 54 & 2.090 & pos & (pos) & S.m. \\
\hline 3 & Mozambique & Occupational & 28 & 42 & 2.860 & pos & pos & $\varnothing$ \\
\hline 4 & Ethiopia & Occupational & 27 & 43 & 2.650 & pos & $\varnothing$ & $\varnothing$ \\
\hline 5 & Uganda & Occupational & 38 & 56 & 1.920 & pos & pos & $\varnothing$ \\
\hline 6 & Uganda & Occupational & 20 & 32 & 1.600 & pos & pos & n.a. \\
\hline 7 & Malawi & Tourist & 18 & 20 & 1.050 & pos & pos & n.a. \\
\hline 8 & Mozambique & Tourist & 35 & 56 & 33.050 & pos & $\varnothing$ & n.a. \\
\hline 9 & Yemen & Tourist & 40 & 54 & 1.540 & pos & pos & $\varnothing$ \\
\hline 10 & Malawi & Tourist & 27 & 35 & 980 & pos & $\varnothing$ & $\varnothing$ \\
\hline $11^{(3)}$ & Kenya & Tourist & 94 & 96 & 3.220 & $\varnothing$ & pos & $\varnothing$ \\
\hline 12 & Kenya & Tourist & 184 & 302 & 1.100 & pos & pos & $\varnothing$ \\
\hline 13 & Sudan & Occupational & 27 & 33 & 3.350 & pos & $\varnothing$ & $\varnothing$ \\
\hline 14 & Tanzania & Volunteer & 75 & 88 & 5.880 & pos & pos & n.a. \\
\hline 15 & East Africa & Volunteer & 127 & 131 & 1.760 & pos & pos & $\varnothing$ \\
\hline $16^{(4)}$ & Kenya & VFR & 150 & 210 & n.a. & pos & n.a. & S.m. \\
\hline 17 & Uganda & Tourist & 24 & 27 & n.a. & pos & pos & n.a. \\
\hline 18 & Malawi & Tourist & 31 & 73 & 3.920 & pos & $\varnothing$ & n.a. \\
\hline 19 & East Africa & Volunteer & 32 & 104 & 4.010 & pos & pos & $\varnothing$ \\
\hline 20 & Malawi & Tourist & 31 & 34 & 1.780 & $\varnothing$ & $\varnothing$ & $\varnothing$ \\
\hline 21 & Mali & Occupational & 23 & 32 & 1.140 & pos & $\varnothing$ & $\varnothing$ \\
\hline 22 & Tanzania & Volunteer & 62 & 66 & 2.800 & pos & $\varnothing$ & $\varnothing$ \\
\hline 23 & Madagascar & Tourist & 35 & 38 & 2.640 & pos & pos & n.a. \\
\hline 24 & Madagascar & Occupational & 92 & 261 & 890 & pos & pos & n.a. \\
\hline 25 & Madagascar & Occupational & 122 & 152 & 870 & pos & pos & $\varnothing$ \\
\hline 26 & East Africa & Tourist & 24 & 36 & 3.150 & pos & pos & $\varnothing$ \\
\hline 27 & Tanzania & Volunteer & 47 & 76 & 1.700 & pos & pos & S.m. \\
\hline 28 & Tanzania & Volunteer & 47 & 80 & 9.850 & pos & pos & $\varnothing$ \\
\hline 29 & Tanzania & Volunteer & 62 & 94 & 2.310 & pos & pos & $\varnothing$ \\
\hline 30 & Tanzania & Volunteer & 97 & 196 & 2.290 & $\varnothing$ & pos & $\varnothing$ \\
\hline 31 & Madagsacar & Occupational & n.a. & 160 & 1.100 & pos & pos & $\varnothing$ \\
\hline 32 & Madagascar & Tourist & 17 & 43 & 1.020 & pos & pos & S.m. \\
\hline $33^{(5)}$ & Ghana & VRF & 31 & 69 & 1.200 & pos & pos & n.a. \\
\hline 34 & Madagascar & Tourist & 23 & 34 & 1.210 & pos & pos & n.a. \\
\hline 35 & Uganda & Tourist & 41 & 53 & 2.900 & pos & $\varnothing$ & n.a. \\
\hline 36 & Madagascar & Tourist & 25 & 42 & 23.300 & pos & pos & S.m. \\
\hline 37 & Ghana & Tourist & 40 & 46 & 1.660 & pos & pos & n.a. \\
\hline 38 & Tanzania & Tourist & 27 & 119 & 2.340 & pos & pos & n.a. \\
\hline
\end{tabular}

(1): Time from exposure to beginning of clinical symptoms.

(2): Time from exposure to diagnostics.

(3): Less than $2 \mathrm{ml}$ of Serum was available for DNA extraction.

(4): Patient evaluated for liver transplantation due to known Hepatitis B Virus infection and eosinophilia after visiting her family.

(5): Patient with meningitis and eosinophils in cerebrospinal fluid, Schistosoma DNA detected by PCR in cerebrospinal fluid.

VFR Visiting relatives and friends.

n.a. Not available.

pos Positive.

$\varnothing$ Negative.

(pos) Only one of two different serological tests for schistosomiasis shows a positive result.

S.m. eggs of S.mansoni. 
according to local protocols was offered to every patient with a positive test result.

\section{Results}

Thirty-eight patients fulfilled the case definition (Group A). Four of them had a history of possible previous exposure to Schistosoma-contaminated water but had not developed symptoms after the first trip. The median time from the day of possible exposure to the onset of clinical symptoms and the median time from exposure to PCR were 35 days (range 12-184 days) and 61 days (range 20-302 days), respectively. Twelve of the patients presented within 6 weeks after the suspected exposure, the time span generally referred to as prepatent stage of S. mansoni. The median absolute eosinophil count was 2,290 $\mathrm{\mu l}^{-1}$ (range $870-33,050 \mu^{-1}$ ). The various members of the study population have been travelled to 17 different African and Arabic countries with endemic schistosomiasis. The median age of the study population was 28 years (range $19-66$ yr) and 76\% were males. Reasons for travelling included: tourism $(48 \% ; n=19)$, occupational travel $(23 \% ; n=9)$, volunteer $(21 \% ; n=8)$ and visiting friends and relatives $(8 \% ; n=3)$. The patients' characteristics are summarized in Table 1.

Initial real-time PCR testing revealed positive detection of Schistosoma DNA in 35 patients. Of the remaining 3 patients with negative PCR results, the first one was part of a four patients cluster. He had an initial eosinophil count of 2,290 $\mathrm{\mu l}^{-1}$ and a positive serology. The three other patients in this cluster were positive by means of serology and PCR. All received Praziquantel early in the course of the disease and subsequently, laboratory results normalized and clinical symptoms resolved. Accordingly, the negative PCR result in this case was considered as false negative. The second patient with a negative PCR test result was considered true negative, since microscopy and serology remained negative during follow up. The third patient with a negative PCR test result provided only a small amount of serum for PCR testing of less than $2 \mathrm{ml}$. In favour of a conservative estimation we interpreted this result as false negative because serology was clearly positive and symptoms resolved after Praziquantel treatment. Thus blood based real-time PCR was able to detect acute schistosomiasis in 35 of 37 true positive patients (95\%). In contrast, antischistosoma antibodies or Schistosoma eggs were detected in only $72 \%$ and $25 \%$, respectively, of these patients.

For 8 patients follow-up data were available. Four patients presented with negative real-time PCR at their follow up visit. The remaining 4 demonstrated a significant decrease in Ct-values. Median follow-up times of patients with positive PCR test results versus patients with negative PCR test results were 6 and 18 months respectively (data not shown).

In addition, 17 patients (Group B) with high clinical suspect for acute schistosomiasis but without an episode of fever were tested (Table 2). The incubation time and the time from exposure to diagnostic work up was 38 days (range 14-93 days) and 64 days (range 17-96 days), respectively. Sixteen patients were males. The median age was 13 years (range: $6-60 \mathrm{yr}$ ) and the median eosinophil count was 1,960 $\mathrm{\mu l}^{-1}$ (range 1,040-14,270 $\mathrm{\mu l}^{-1}$ ). The decision for testing these patients was based on high eosinophil counts, a history of recent travelling to a schistosomiasis endemic region and at least one of the following symptoms: fatigue, gastro-intestinal symptoms, rash or exanthema. Blood based real-time PCR testing was negative in 5 of these patients. In these 5 patients, initial serological testing revealed a positive result in one patient and inconclusive results in two patients. On follow up visits, all of them were serologically negative. Microscopic examination of stool samples was negative in all patients at initial presentation and during follow up. Of the remaining 12 patients, one was returning from Togo with positive serology and microscopy and the other 11 were part of a travel group returning from Rwanda. In this cluster reported earlier [15], PCR was positive in all of them, whereas positive serology or microscopy at initial testing was detected in only 7 of them.

\section{Discussion}

To our knowledge this is the first multicenter study on acute schistosomiasis in travellers residing in nonendemic countries. Moreover, it constitutes the largest prospective study on a blood based real-time PCR for the diagnosis of the disease. The high rate of positive PCR results within the study population may be in part attributed to the fact that the participating centres are well familiar with this otherwise rare disease of acute schistosomiasis as all centres are specialized in travel and tropical medicine.

The results presented here support previous findings that PCR for the detection of Schistosoma DNA in serum outperforms other diagnostic test such as serology or microscopy in the early phase of the infection, particular in the prepatent stage of human schistosomiasis [14], as demonstrated by the twelve patients presenting within 42 days after the suspected exposure. By PCR, a correct diagnosis was made in $95 \%$ of patients, despite the heterogeneous characteristics of the study population (17 endemic countries - cluster and single patients), which underlines the robustness of blood base real-time PCR testing for the diagnosis of acute schistosomiasis. In addition, PCR was able to exclude active Schistosoma infections in six patients, of whom $50 \%$ were suspected due to positive serology (1 positive, 2 inconclusive). 
Table 2 Characteristics of patients with high suspicion of acute schistosomiasis but without fever

\begin{tabular}{|c|c|c|c|c|c|c|c|c|}
\hline Patient & $\begin{array}{l}\text { Region of } \\
\text { exposure }\end{array}$ & $\begin{array}{c}\text { Reason for } \\
\text { travel }\end{array}$ & $\begin{array}{l}\text { Incubation time } \\
\text { [days] }]^{(1)}\end{array}$ & $\begin{array}{l}\text { Time to diagnosis } \\
\text { [days] }]^{(2)}\end{array}$ & $\begin{array}{l}\text { Eosinophils absolute } \\
\text { [per } \mu \mathrm{l}]\end{array}$ & PCR & Serology & Microscopy \\
\hline 39 & Togo & VFR & 51 & 95 & 6,000 & pos & pos & S.m. \\
\hline 40 & Brazil & Tourist & 39 & 66 & 11,640 & $\varnothing$ & $\varnothing$ & $\varnothing$ \\
\hline 41 & Guinea & Tourist & 14 & 17 & 1,090 & $\varnothing$ & pos & $\varnothing$ \\
\hline 42 & Uganda & Occupational & 38 & 44 & n.a. & $\varnothing$ & pos & n.a. \\
\hline 43 & Egypt & Tourist & 26 & 40 & 1,100 & $\varnothing$ & $\varnothing$ & $\varnothing$ \\
\hline 44 & Malawi & Tourist & 37 & 40 & 1,040 & $\varnothing$ & (pos) & $\varnothing$ \\
\hline 45 & Rwanda & Tourist & 47 & 54 & 2,640 & pos & $\varnothing$ & S.m. \\
\hline 46 & Rwanda & Tourist & 62 & 90 & 14,150 & pos & pos & S.m. \\
\hline 47 & Rwanda & Tourist & 57 & 62 & 1,150 & pos & $\varnothing$ & $\varnothing$ \\
\hline 48 & Rwanda & Tourist & 93 & 96 & 2,860 & pos & (pos) & S.m. \\
\hline 49 & Rwanda & Tourist & 25 & 54 & 14,270 & pos & pos & S.m. \\
\hline 50 & Rwanda & Tourist & n.a. & 96 & 11,120 & pos & pos & S.m. \\
\hline 51 & Rwanda & Tourist & n.a. & 96 & 1,960 & pos & pos & $\varnothing$ \\
\hline $52^{(3)}$ & Rwanda & Tourist & n.a. & 62 & 1,290 & pos & $\varnothing$ & $\varnothing$ \\
\hline $53^{(3)}$ & Rwanda & Tourist & n.a. & 96 & 1,210 & pos & (pos) & s.m. \\
\hline $54^{(3)}$ & Rwanda & Tourist & n.a. & 96 & 2,120 & pos & (pos) & $\varnothing$ \\
\hline $55^{(3)}$ & Rwanda & Tourist & n.a. & 96 & 1,700 & pos & pos & S.m. \\
\hline
\end{tabular}

(1): Time from exposure to beginning of clinical symptoms.

(2): Time from exposure to diagnostics.

(3): Persons from cluster, exposed 2 years before at the same location as well, and not previously diagnosed.

VFR Visiting relatives and friends.

n.a. Not available.

pos Positive.

$\varnothing$ Negative.

(pos) Only one of two different serological tests for schistosomiasis shows a positive result.

S.m. eggs of S.mansoni.

Thus, the results support previous observations that the PCR test system used in this study is highly sensitive and specific [14]. Accordingly, this test system has substantial added value for an early and rapid decision making to circumvent cost-intensive and time-consuming diagnostic procedures and to prevent unnecessary therapies. Cost for one PCR test (materials and reagents) are roughly 2 US\$, thus the test is a useful addition in the differential diagnosis in patients with fever and eosinophilia after travelling to schistosomiasis endemic countries but is not generally recommended as a screening assay for returning travelers.

A considerable disadvantage of classical Schistosoma diagnostics is the persistence of serologic markers and egg shedding after successful treatment. Previous studies in experimentally infected mice [14] suggested that blood based real-time PCR testing might be suitable not only for initial diagnosis but also for follow up monitoring. This is further supported by our findings in 8 patients, for whom follow up data were available. These results suggest a significant decline in Ct-values in response to treatment. Clearly negative PCRs are expected after a longer period of time due to the high sensitivity of PCR and the carry over of DNA from slowly degenerating eggs in the tissue. However, for a definite conclusion on the usefulness of PCR for monitoring of schistosomiasis treatment the follow-up of a larger number of patients is required.

The highly repetitive 121 bp DNA fragment used as target sequence in the real-time PCR assay constitutes about $12 \%$ of the S. mansoni genome [20]. Although this sequence is detected in $S$. haematobium and $S$. japonicum as well $[20,21]$ sensitivity of PCR for the latter two species might be reduced. As far as species could be determined by microscopic egg morphology, the vast majority of cases in this study were due to infections by $S$. mansoni. Thus, our results may not allow generalization to infections with Schistosoma species other than S. mansoni. Evaluation of blood based PCR for the diagnosis of acute schistosomiasis due to other Schistosoma species such as S. haematobium or $S$. japonicum requires further studies. Previous results with the assay used in this study indicated that the performance of the PCR using the $121 \mathrm{bp}$ tandem target sequence on $2 \mathrm{ml}$ serum samples works very well in S. mansoni infection, but not in S. haematobium and in S. mekongi infection (Jan Clerinx, personal communication). Likewise, additional studies are required to evaluate 
the usefulness of blood-based PCR for the diagnosis of chronic schistosomiasis, in particular, in suspected cases from endemic countries, with a positive serology but negative parasite microscopy. Moreover, recent studies on, PCR performed with urine or fecal samples to detect $S$. haematobium or S. mansoni infection have shown rather promising results [22-25]. However, further studies are required to determine, whether urine and/or feces PCR is sensitive to detect early schistosoma infection as it is the case in patients with acute schistosomiasis.

\section{Conclusion}

For the early diagnosis of acute schistosomiasis, realtime PCR for the detection of Schistosoma DNA in serum is more sensitive than classic diagnostic tools such as serology or microscopy, irrespective of the region of infection. Generalization of the results to all Schistosoma species may be difficult as in the study presented here only eggs of $S$. mansoni were detected by microscopy. A minimum amount of two millilitre of serum is required for sufficient diagnostic accuracy.

\section{Competing interests}

All authors declare to have no competing interests.

\section{Authors' contribution}

GDB, ET and DW designed the study protocol. JC, SD, MJ, PP, JR, MS, AS, PS, GDB and DW coordinated the study at their local institution, including collection of patients data and clinical specimens. SV, JC, SD, MJ, PP, JR, MS, AS, PZ and ET were responsible for performing serological tests, analysis and interpretation of the data. SV, HVT and ET were responsible for performing PCR tests, analysis and interpretation of the data. SV, JC, ET and DW performed the statistical analysis. SV, ET and DW drafted the manuscript. JC and PP account for the critical revision of the manuscript. All authors have given approval to the final version of the manuscript.

\section{Acknowledgement}

The study was funded by grant support from the Bernhard Nocht Institute for Tropical Medicine, Hamburg, Germany. The funding source had no role in the design, conduct or reporting of the study or to submit the manuscript for publication.

\section{Author details \\ 'Department of Intensive Care Medicine, University Medical Centre Hamburg-Eppendorf, 20246, Hamburg, Germany. ${ }^{2}$ Bernhard Nocht Institute for Tropical Medicine, Hamburg, Germany. ${ }^{3}$ Department of Clinical Sciences, Institute for Tropical Medicine Antwerp, Antwerp, Belgium. ${ }^{4}$ Institute of Tropical Medicine \& International Health, Charité Universitätsmedizin Berlin, Berlin, Germany. ${ }^{5}$ Department of Infectious Diseases, Oslo University Hospital, Oslo, Norway. ${ }^{6}$ Department of Infectious Diseases an Tropical Medicine, Hôpital Nord, Marseille, France. ${ }^{7}$ Department of Gastroenterology, Hepatology and Infectious Diseases, Heinrich Heine University Duesseldorf, Duesseldorf, Germany. ${ }^{8}$ Department for Infectious Diseases and Tropical Medicine, Ludwig Maximilian University Munich, Munich, Germany. ${ }^{9}$ Missionsaerztliche Klinik, Wuerzburg, Germany. ${ }^{10}$ Institute of Tropical Medicine, Eberhard Karls University, Tuebingen, Germany. ${ }^{11}$ Department of Tropical Medicine, University Medical Centre Hamburg-Eppendorf, Hamburg, Germany.}

Received: 6 October 2012 Accepted: 21 January 2013

Published: 30 January 2013

\section{References}

1. Chitsulo L, Engels D, Montresor A, Savioli L: The global status of schistosomiasis and its control. Acta Trop 2000, 77:41-51.

2. Strickland GT RB: Schistosomiasis. In Hunter's Tropical Medicine. Eighthth edition. Edited by Strickland GT. Philadelphia, PA: W.B. Saunders Company; 2000:804-832.

3. Doherty JF, Moody AH, Wright SG: Katayama fever: an acute manifestation of schistosomiasis. BMJ (Clinical research ed 1996, 313:1071-1072.

4. Jaureguiberry S, Paris L, Caumes E: Acute schistosomiasis, a diagnostic and therapeutic challenge. Clin Microbiol Infect 2010, 16:225-231.

5. Ross AG, Vickers D, Olds GR, Shah SM, McManus DP: Katayama syndrome. Lancet Infect Dis 2007, 7:218-224.

6. Knopp S, Rinaldi L, Khamis IS, Stothard JR, Rollinson D, Maurelli MP, Steinmann P, Marti H, Cringoli G, Utzinger J: A single FLOTAC is more sensitive than triplicate Kato-Katz for the diagnosis of low-intensity soiltransmitted helminth infections. Trans R Soc Trop Med Hyg 2009, 103:347-354.

7. Cesari IM, Ballen DE, Mendoza L, Matos C: Detection of Schistosoma mansoni membrane antigens by immunoblot analysis of sera of patients from low-transmission areas. Clin Diagn Lab Immunol 2005, 12:280-286.

8. Hamilton JV, Klinkert M, Doenhoff MJ: Diagnosis of schistosomiasis: antibody detection, with notes on parasitological and antigen detection methods. Parasitology 1998, 117(Suppl):S41-S57.

9. Zhu YC: Immunodiagnosis and its role in schistosomiasis control in China: a review. Acta Trop 2005, 96:130-136.

10. Rabello AL, Garcia MM, da Silva RA P, Rocha RS, Katz N: Humoral immune responses in patients with acute Schistosoma mansoni infection who were followed up for two years after treatment. Clin Infect Dis 1997, 24:304-308

11. Coulibaly JT, Knopp S, N'Guessan NA, Silue KD, Furst T, Lohourignon LK, Brou JK, N'Gbesso YK, Vounatsou P, N'Goran EK, Utzinger J: Accuracy of Urine Circulating Cathodic Antigen (CCA) Test for Schistosoma mansoni Diagnosis in Different Settings of Cote d'Ivoire. PLoS Negl Trop Dis 2011, 5:e1384

12. Shane HL, Verani JR, Abudho B, Montgomery SP, Blackstock AJ, Mwinzi PN, Butler SE, Karanja DM, Secor WE: Evaluation of urine CCA assays for detection of Schistosoma mansoni infection in Western Kenya. PLoS Negl Trop Dis 2011, 5:e951.

13. Gundersen SG, Ravn J, Haagensen I: Early detection of circulating anodic antigen (CAA) in a case of acute schistosomiasis mansoni with Katayama fever. Scand J Infect Dis 1992, 24:549-552.

14. Wichmann D, Panning M, Quack T, Kramme S, Burchard G-D, Grevelding C, Drosten C: Diagnosing schistosomiasis by detection of cell-free parasite DNA in human plasma. PLoS Negl Trop Dis 2009, 3:e422.

15. Clerinx J, Bottieau E, Wichmann D, Tannich E, Van Esbroeck M: Acute schistosomiasis in a cluster of travelers from Rwanda: diagnostic contribution of schistosome DNA detection in serum compared to parasitology and serology. J Travel Med 2011, 18:367-372.

16. Feldmeier H, Stevens WJ, Bridts CH, Daffalla AA, Büttner DW: Effect of chemotherapy and reinfection on IgE-containing and IgG-containing circulating immune complexes, serum lgE and lgE antibodies in patients chronically infected with Schistosoma mansoni and Schistosoma haematobium. Int Arch Allergy Appl Immunol 1983, 72:211-218.

17. Peters PA, Mahmoud AA, Warren KS, Ouma JH, Siongok TK: Field studies of a rapid, accurate means of quantifying Schistosoma haematobium eggs in urine samples. Bull World Health Organization 1976, 54:159-162.

18. Feldmeier H, Büttner DW: Immunodiagnosis of Schistosomiasis haematobium and schistosomiasis mansoni in man. Application of crude extracts from adult worms and cercariae in the IHA and the ELISA. Zentralbl Bakteriol Mikrobiol Hyg [A] 1983, 255:413-421.

19. Tarp B, Black FT, Petersen E: The immunofluorescence antibody test (IFAT) for the diagnosis of schistosomiasis used in a non-endemic area. Trop Med Int Health 2000, 5:185-191.

20. Hamburger J, Turetski T, Kapeller I, Deresiewicz R: Highly repeated short DNA sequences in the genome of Schistosoma mansoni recognized by a species-specific probe. Mol Biochem Parasitol 1991, 44:73-80.

21. Hamburger J, He N, Abbasi I, Ramzy RM, Jourdane J, Ruppel A: Polymerase chain reaction assay based on a highly repeated sequence of Schistosoma haematobium: a potential tool for monitoring schistosomeinfested water. Am J Trop Med Hyg 2001, 65:907-911. 
22. Ibironke OA, Phillips AE, Garba A, Lamine SM, Shiff C: Diagnosis of Schistosoma haematobium by detection of specific DNA fragments from filtered urine samples. Am J Trop Med Hyg 2011, 84:998-1001.

23. Ibironke O, Koukounari A, Asaolu S, Moustaki I, Shiff C: Validation of a new test for Schistosoma haematobium based on detection of Dra1 DNA fragments in urine: evaluation through latent class analysis. PLoS Negl Trop Dis 2012, 6:e1464.

24. Enk MJ, Oliveira E, Silva G, Rodrigues NB: Diagnostic accuracy and applicability of a PCR system for the detection of Schistosoma mansoni DNA in human urine samples from an endemic area. PLOS ONE 2012, 7:e38947.

25. Cnops L, Tannich E, Polman K, Clerinx J, Van Esbroeck M: Schistosoma real-time PCR as diagnostic tool for international travellers and migrants. Trop Med Int Health 2012, 17:1208-1216.

doi:10.1186/1471-2334-13-55

Cite this article as: Wichmann et al:: Prospective European-wide

multicentre study on a blood based real-time PCR for the diagnosis of acute schistosomiasis. BMC Infectious Diseases 2013 13:55.

\section{Submit your next manuscript to BioMed Central and take full advantage of:}

- Convenient online submission

- Thorough peer review

- No space constraints or color figure charges

- Immediate publication on acceptance

- Inclusion in PubMed, CAS, Scopus and Google Scholar

- Research which is freely available for redistribution 